\title{
Impacts of New Technologies on Free-to-Air TV industry: Lessons from Selected Country Cases
}

\author{
Esther Menezes, Ruy de Quadros Carvalho'
}

\begin{abstract}
This paper aims to examine the impacts of new technologies, especially of the digital TV, on the industry of terrestrial TV in selected countries. Taking the evolution of information and communication technologies (ICTs) as a background scenario, the transformations provoked by digitization of TV on the following aspects are analyzed: (i) the market structure of terrestrial TV (or free-to-air TV broadcasting), (ii) the plurality and diversity of TV programming. Based on secondary data and on recent studies on the technological trajectory of terrestrial TV in selected countries, one concludes that digital TV may provide great opportunities for development in such industry, but the magnitude of its benefits is strongly conditioned by socioeconomic factors and by how the service was regulated. Such findings may contribute to Brazilian debate on development opportunities opened by technological change to the television sector.

Keywords: technological change; diffusion of new technologies; information and communication technologies; free-to-air TV broadcasting; terrestrial television industry; digital terrestrial TV technology; market structure; media plurality or diversity; regulation.
\end{abstract}

\footnotetext{
' Science and Technology Policy Division. University of Campinas - Unicamp. João Pandiá Calógeras, 5I CEP I3083-870.

Phone/fax: +55 19 35214555. Campinas, SP, Brazil. (Corresponding authors) Email: esthermene@gmail.com, ruyqc@ige.unicamp.br
} 


\section{Introduction}

Fundamental technological changes have occurred in the television industry in last decades. Preceded by the introduction of new technologies alternatives to terrestrial TV, e. g. cable and satellite TV, the most recent (and ongoing) technological transformation is the digitization of the content and of the existing television transmission platforms.

In Brazil, the digitization of free-to-air terrestrial $\mathrm{TV}^{2}$ may induce relevant transformations in an industry characterized by the high concentration of audience (Bolaño and Brittos, 2007), whose importance is attested by the presence of TV sets in more than $90 \%$ of households, most of them with no pay TV services ${ }^{3}$.

Basically, the advantages of the digital TV (DTV) derive from its high capacity of data transmission. Such feature allows offering new TV channels, higher quality image and interactive services, which potentially would enable new actors participating in the television industry. Therefore, the current structure of such market would change dramatically. This is the reason why the introduction of the new technology is seen by many as a window of opportunity to reinforce democratization of communications and plurality of points of view (Galperin, 2003; Bolaño and Britto, 2007).

On the other hand, the potentials of the new technology have been a source of concern for the traditional actors of the TV sector in Brazil. Representatives of Brazilian terrestrial TV industry are afraid of regulatory changes required to explore the new technology features, which might bring harmful consequences to established broadcasters (see, for example, Pizani, 2005).

In such a context, this paper aims to provide the Brazilian debate with experiences of countries where digital terrestrial TV was introduced. This paper has as background the developments in new information and

\footnotetext{
${ }^{2}$ The term terrestrial TV refers to the technology used to transmit television programming through terrestrial broadcasting. It is also referred as free-to-air TV, which is usually free of charge and can also be transmitted via satellite.

${ }^{3}$ According to 2006 data from IBGE (Brazilian Institute of Geography and Statistics) and ABTA (Brazilian Pay TV Association).
}

communication technologies (ICT), and it examines the possible effects of the digitization of TV in terms of its contribution to foster the development and growth of the television industry in selected countries where digital TV was adopted. Such experiences would show in what extent such technology may benefit or disturb traditional actors of TV market, i.e. the terrestrial TV broadcasters established before the technological transition. Such issues can be summarized in the following question: how digital terrestrial TV can affect (i) market structure, revenue and audience market shares, and (ii) the diversification of information sources, which means more plurality of content and options for viewers.

In search of new possible configurations of the television industry enabled by technological innovations, the development of this paper relied mostly on: (i) research of concrete experiences observed from secondary data; (ii) recent works on the terrestrial TV trajectory in selected countries. The focus on terrestrial TV is due to its social and strategic importance as a public service (European Commission, 2003), especially in Brazilian society.

In the following Section (2), the potential benefits of new technologies to the TV industry are presented under the technological point of view. Section 3 discusses how impacts of new technologies are also shaped by socioeconomic conditions (i.e. purchase power, attractiveness of the new product) and regulatory restrictions (i.e. if the regulation allows employing some new features of digital TV, like the addition in the number of TV programming channels). In order to verify how the diffusion of the new technology occurred and its impacts on the market structure and on plurality and diversity of the content delivered to viewers, Section 4 presents both technological and non-technological factors considered in the analysis of the TV industry in two selected countries (the United States and the United Kingdom). In Sections 5 , these cases are compared. Finally Section 6 evaluates in what extent the main findings could be apply to the Brazilian context in order to get a glimpse of the future of digital TV in Brazil.

\section{Risks and opportunities of technological changes in TV industry}

The development of the digital TV was enabled by the advances in information and communication technologies 
(ICT). Digital data, whatever text, voice or visual content, can be compressed to occupy less storage space and transmission capacity. From such properties derives the main benefit of the digitization, basically the increase in the capacity of data transmission and relative reduction of operational costs of storage, content-editing and transmission.

The digitalization adds more capacity of transmission to terrestrial TV, as well as to other TV platforms (such as cable and satellite). Such feature can be employed in alternative ways: either to transmit more television channels (each one with an individual programming schedule) than in analogue TV or to transmit TV programming with a high definition resolution. Such facilities leave open the possibility of distinct impacts. Equipments used in high definition content production are $20 \%$ more expensive and the additional postproduction costs (since high definition images requires more editing and storage capacity) are from 0 to $100 \%$ higher, depending on the requested quality of the final product. The high definition implies more intensive use of infrastructure capacity of distribution and, therefore, higher costs of packaging and distribution. Moreover, high definition-enabled TV sets are more expensive to consumers, since their processing power has to be higher and the screen larger enough to viewers notice the higher-quality image. Production of such quality content is naturally more accurate: staging, lighting, filming and even artistic production (e.g. makeup of actors) has to be more detailed and rigorous, given that high definition highlights the imperfections of the object being filmed. All these factors imply higher prices of production, transmission and reception of high definition content, which possibly expand the barriers to entry of smaller producers and programmers unable to bear higher initial investment and operational costs (Bajon and Villaret, 2004).

On the other hand, the expansion of television programming resulted from the elimination of technological barriers to entry of new players (i.e. the spectrum scarcity in the case of analogue terrestrial TV) would further lead to a process of audience fragmentation started decades ago with a greater supply of TV channels provided by cable and satellite platforms. The fall in the average audience could gradually devaluate the propaganda, thus undermining the essential pillar of the free-to-air television business model (OECD, 2004b). The abundance of channels provided by the digitalization of TV would therefore aggravate the devaluation of transmission activities in the TV value chain, thus inducing a process of value shift where part of the profitability of transmission goes to other value chain activities, especially to the production of content (Todreas, 1999).

In addition to the expansion in the amount of information being transmitted, the digitization of TV makes possible its integration or convergence with other communications networks. In such technical environment, television services can be provided by alternative networks, such as high-speed network using Internet protocol. They also present huge differentials that the so technically limited terrestrial broadcasting is unable to offer: more flexibility, allowing users to choose the desired content, as well as the time and place of content consumption through the device of his or her choice such as a TV, a computer or a portable terminal (OECD, 2004a).

However, it is worth to remember that technological factors are not the only ones to influence the process of diffusion of innovations. Preston (200I) pointed out that there are a number of non-technological factors inhibiting the transition to a fully multimedia and convergent communications industry with no boundaries between services and networks. Among these factors, one can mention existing industrial cultures, organizational skills and differentiated regulatory conditions between the industries (e.g. telecommunications and television).

In fact, the advance of high-speed Internet, which is seen as a threat to the television market, has been inhibited by its price, which is still high (especially in countries whose population has low purchasing power, such as Brazil ${ }^{4}$ ). Other factors, such as lack of technology standardization and copyright restrictions, also retard the progress of technologies that compete with TV.

4 According to Alves (2009), the number of households with a computer has been increasing significantly in recent years in Brazil, but the cost of Internet services has remained relatively high, which may explain the highest proportion of presence of computer compared to internet services. 
Based on such findings as well as in historical evidence, Preston (200I) argues that in spite of competition between different media, they are foremost complementary, which leads the author to conclude that mass media is likely to keep playing a relevant role at least in the medium term.

\section{Socio-economic and regulatory factors shaping the effects of the digital TV}

Such as other ICT-based services (e.g. telecommunications), mass media communications have economies of scale and scope that favors the generation of oligopolistic or monopolistic market structures.

Economies of scale are resulted from high initial investment costs in TV broadcasting, as well as from the fact that television programming can be received by more than one person simultaneously with no additional costs. The cost of terrestrial transmission is independent of the number of televisions under the broadcast coverage. Such features allow characterizing TV programming as a public good, which means the marginal cost of transmitting programs tends to zero, regardless the cost of content production (Owen and Wildman, 1992).

Once digitalized, the TV has increased its capacity to transmit information under a single network platform. In theory it can reduce the technical and economic barriers to entry and make television programming more easily reproduced and transmitted, i.e. "costly to produce but cheap to reproduce (Shapiro and Varian, 1999, p. 3, italic in original). On the other hand, such mechanism that reduces barriers to entry also strengthens the natural tendency of market to concentrate, since it deepens economies of scale (Shapiro and Varian, 1999; Noam, 2006).

Not only techno-economic factors are related to market concentration. Since market structure has an endogenous component, it is subject to changes induced by the behavior of economic agents in the market (Nelson and Winter, 1977). In the face of a possible entry of new actors, those already established would adopt strategies whose main result is the reinforcement of concentration (Mansell, 2004). The feasibility of such hypothesis can be illustrated by the example of the ICT market, where the trend of concentration prevails, although new technologies open up the possibility of "disrupting the structure of older media and communications markets" (Mansell, 2004, p.99). In the particular case of the TV sector, an environment of abundant channels may encourage actors to choose strategies of vertical integration of content production in order to offset the bargaining power of other producers. Another example of strategy of preservation is the product differentiation, which can be obtained through the offer of high definition content. Due to its high costs of production and transmission (mentioned in Section 2), the offer of such kind of content may increase barriers to entry of new firms in the market.

The above mentioned dynamics of market structure in the face of new technologies are conditioned by several nontechnological factors. In the particular case of the television industry, the regulation of TV services weighs decisively on its development. Given its universal service character, terrestrial TV-based service has always been highly regulated. The use of spectrum, a public good whose scarcity confers characteristics of natural monopolies to the television industry, and the tendency to generate negative externalities, such as the delivery of socially undesirable content, impose needs of stronger regulation. Besides inhibiting market power abuse, regulation in TV market would assume the role of encouraging the production of merit goods, defined in Katz (2006) as those ones whose production is seen as needed in a higher volume than the capacity of absorption by the market, or goods that are socially useful despite having no monetary value. From educational programs to national and local content, the massive diffusion of such goods is considered desirable and convenient due to their contribution to social welfare (OECD, 2004a; Katz, 2006).

Although new technologies bring the potential of enabling new products and services - they are enablingtechnologies as referred by Mansell (2004) - different alternatives of exploration are often mutually exclusive. Thus the decision on a model of exploration, i.e. what features will be allowed to commercial exploration, may limit the employment of all features. Such decision is influenced by social, political and cultural factors that "enable some choices and preclude others" (Galperin, 2004b, p.162). Galperin (2004b) emphasizes that the political and institutional arrangements, interest groups and legal regulatory framework impose difficulty to implement a scenario where the benefits of a technology 
are fully employed, even in cases which there are no technical restrictions to employ all of them. Moreover, the past history, formed from political decisions and past business strategies, makes change costly to players that are already on the market (path-dependence), which explains their resistance to "policies which significantly alter the established rules of the game, thus facilitating policy choices consistent with the existing institutional regime" (Galperin, 2004b, p. 165).

Therefore, according to Galperin (2004b), regulation of digital TV can be influenced by the current regulation of analog TV service, including the possibility of a scenario in which the implications of digital terrestrial TV may not differ substantially from the older technology. All these non-technological factors also explain why the same technology can present different trajectories in different countries.

Finally, it is worth to stress that the extent to which benefits from the new technologies would be appropriated by society depends on the promotion of changes in the regulation of TV towards the participation of more players in such market, as well as the diversity of opinions and points of view. However, although it may be a necessary condition, a more competitive environment itself would not guarantee the diversity of television programming. First, because most revenues got by free-to-air TV companies are provided by advertisers, not by viewers. In other worlds, free-toair TV sells audience, not programs (Owen and Wildman, 1992). Advertisers also tend to associate their advertising with mass-audience programs. Such fact gave rise to the phenomenon known as "the paradox of multiple channels", which means abundant supply of homogeneous content even in an environment of free choice programming (OECD, 2004b). In addition, concentrated markets favor high profit margins which may favor the production of high-quality content (European Commission, 2007, Motta and Polo, 1997), which indicates that the production of large amounts of content and economic efficiency might be conflicting.

\section{The international experience}

As the United States and the United Kingdom were pioneers in the adoption of digital terrestrial TV, they have a longer time experience to be observed. They also have the greatest set of industry data available. Additionally, as Galperin (2004a) pointed out, such countries are the best illustration of the fact that the adoption of a given technology may present very different effects in distinct countries due to non-technological constraints.

\section{The United Kingdom}

The free-to-air television sector in United Kingdom consists on broadcasters (i.e. TV transmission companies) and by publicly owned or private programming companies, which receive public transfers whose source is an annual fee paid by owners of television and radio sets. The public transfers destined to a company are proportional to all the obligations which it is required to carry out, e.g. the transmission of a minimum percentage of certain types of programs and independent content, and others that the regulator may establish (Ofcom, 2006).

The digital terrestrial TV was introduced in the United Kingdom in 1998, when around $27 \%$ of households had a TV service subscription. The exploration of the new technology was regulated so as to allow the provision of a number of digital TV programming channels higher than that of analogue television, with a standard definition image. Each broadcaster, including those already established in the market, was also allowed to offer more than one digital channel. Such option intended to expand the possibility of choices and to benefit the industry by offering more variety of interactive services, providing a more efficient use of frequency spectrum allocated to communications services and stimulating competition (Goodwin, 2005).

In 2007, the proportion of households with terrestrial digital TV reached $60 \%$ in United Kingdom, and 33\% had only the terrestrial TV service (according to data illustrated on Figure I). 
UNITED KINGDOM

Households with TV sets (\%)

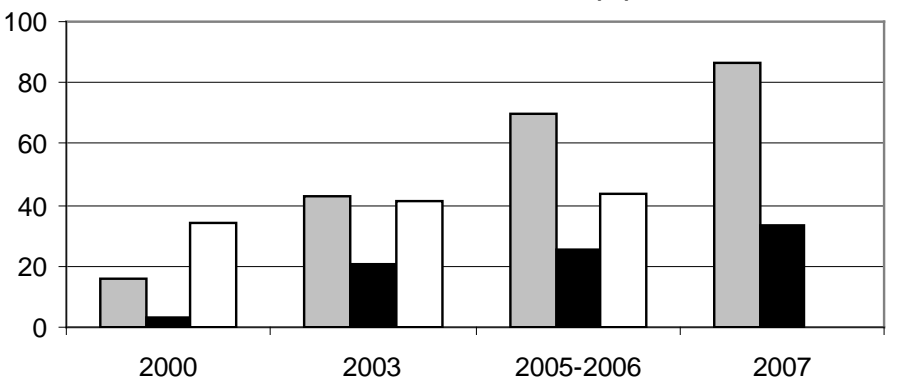

口 Digital TV (cable, sat. \& terrestrial)

- Terrestrial Digital TV-only (1st. Quarter.) 口Pay TV

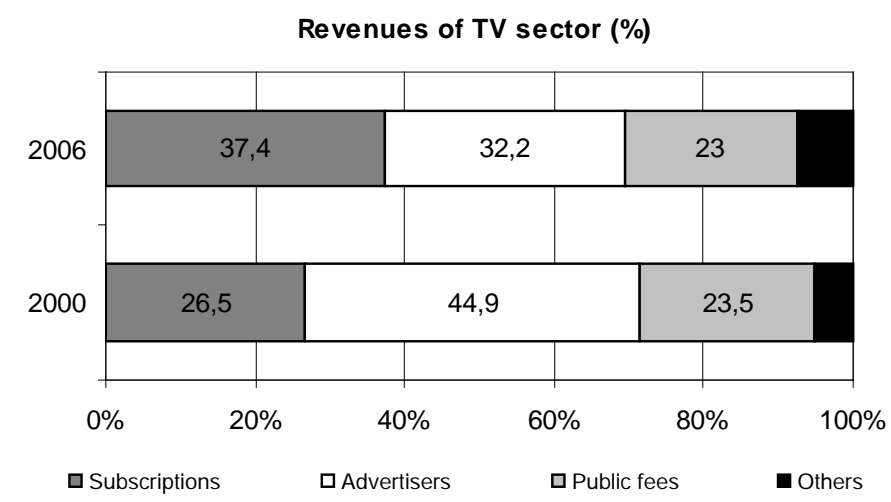

Audience of four main terrestrial TV companies (\%)

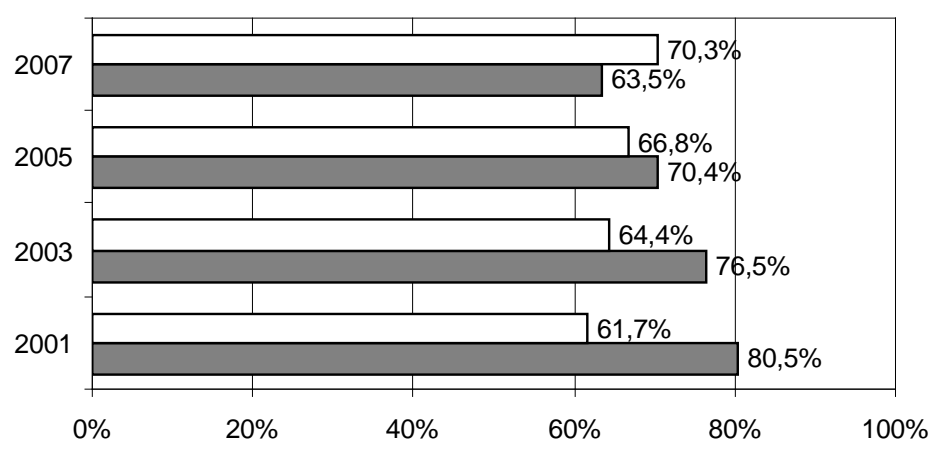

口Portfolio of channels (on the total of households with cable TV, sat. \& terrest. digital TV)

口Tradicional channels (on the total of households)

Figure I.TV market in the United Kingdom. Data based on Ofcom (2006 and 2007) and OECD (2007).

After digitization of terrestrial TV, transmission and programming remained distinct functions assigned to different actors, respectively network operators and television programmers, which have been practiced since 1997, when the BBC had outsourced its network transmission.

According to Figure I, the audience of the four main freeto-air television companies has fallen. However, the same companies has been offering a set (or portfolio) of digital channels, delivered through both pay TV and digital terrestrial platforms, whose aggregated audience has grown. Therefore, one can deduce that the average audiences of these companies have been sustained by the multiple digital channels they started to offer through terrestrial digital TV, as well as in pay TV packages. Combined with the strength of their consolidated brands, which is a crucial factor of attractiveness of their new channels, the strategy of offering more channels may have benefited those major traditional companies by preserving their competitiveness in the face of pay TV services (Ofcom, 2006).

Revenues from pay TV subscriptions (satellite and cable) have intensely grown and exceeded those from advertising since 2003, according to Ofcom (2006). Recently, they have been accounting for one third of the total revenue of the whole TV market (which includes advertising and subscription revenues, license fees and public funds, among others). With respect to advertising revenue, the growth of such source has been lower among traditional channels than that observed in the pay TV market.

According to Raven, et al. (2004), the historical trend points to a sharp drop in prices paid by advertisers to broadcast advertisements, fact that the authors attributed to the Internet boom. Given the expected emergency of new channels, which should reduce the average audience 
per channel, the downward trend in advertising revenues must persist in the long term. It is worth noticing that there were 236 channels of TV programming in 2002, against 433 in 2006 (Ofcom, 2007).

Regarding the content production sector in the UK, it is dominated by those TV companies which have its own production capacity (such as BBC and ITV). Only BBC responded for $45 \%$ of the total investment in new content in 2006, including both own and independent production. Nevertheless, the independent sector has grown. The seven major independent content producers account for a total of $46 \%$ of industry revenues. Individually, each one have a market share ranging between $3 \%$ and $10 \%$ of total revenues, according to Ofcom (2006). From the total hours of programming, BBC channels offered $31 \%$ of independent production in 2005 against 33\% of ITV offer, $82 \%$ of Channel 4 and $88 \%$ of Five. One can infer therefore that larger TV companies tend to take advantages from economies of scale and scope through the internalization (or vertical integration) of the content production, while smaller firms rely rather on third-party content to fill its program schedule.

When analyzing the information above, one notices that the expansion in the number of channels has been the most relevant factor of success for terrestrial digital TV in UK. Although traditional channels have lost market share to the multiple channels services provided by pay TV, the offer of multiple digital programs instead of a single analog TV programming, combined with the high public acceptance achieved by traditional analog channels over the years, has contributed to strengthen the traditional free-to-air TV companies, preventing further losses of market share in the face of intense competition performed by pay TV channels.

Assuming the trend of growing participation in audience of multiple channels suggested by Raven, et al. (2004), one can conclude that the shift of terrestrial TV industry towards the offer of a greater number of channels has been fundamental to favor those companies already present in the traditional terrestrial TV sector in UK. In this sense, the digitalization of terrestrial TV, combined with a regulation which allows offering a greater variety of channels, contributed, above all, to strengthen the existent terrestrial TV companies in United Kingdom. Regarding competition, traditional established TV companies started themselves offering many alternative TV programming schedules.

Although the data do not allow to evaluate accurately qualitative aspects of plurality and diversity, they show at least an increasing demand for content by traditionally well-established companies with the greatest market shares (such as BSkyB, which is one of the content suppliers for terrestrial digital TV programmers). It represents a fundamental stimulus to independent production. Judging by the relevant percentage of independent content delivered by broadcasters, the fact that independent content compose a relevant amount in programs may be explained by the legal requirement to offer at least few hours of content from third parties rather than by technological advances themselves. Nevertheless, the increase of absolute demand for content would not be possible without a larger number of channels enabled by technological advances, which in turn would lead to an increase in the demand for independent content.

To sum up, the introduction of terrestrial digital TV contributed to further development of TV market in the UK not only by increasing the number of actors in the activities of content production and programming but also by benefiting the traditional actors. Although there are more content being offered through new channels, it is hard to qualitatively assess if such development has contributed decisively to more diversity in the programming and transmission activities. Objectively, one notices that the traditional free-to-air TV programmers already established before the introduction of digital TV still offer a relevant proportion of all content and remain dominating the content production.

\section{The United States}

The US terrestrial TV transmission market is formed by a set of few major TV networks (including public-owned ones), networks affiliated to the largest commercial ones (the majority) and independent stations. All these enterprises have their own network infrastructure of transmission and can therefore be so-called either broadcasters or programmers.

Since the introduction of cable TV, the audience of terrestrial TV networks has noticeably declined, according to data exhibited in Figure 2. 


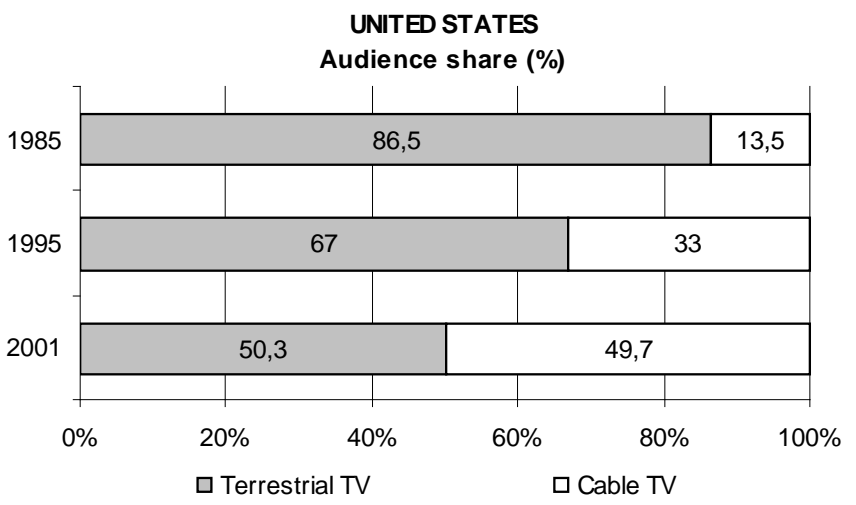

Subscribers (percentage on households)

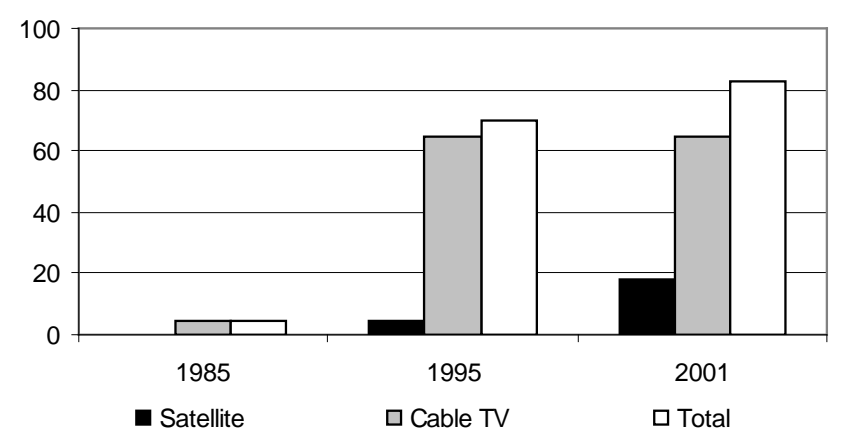

Revenue share (\%)
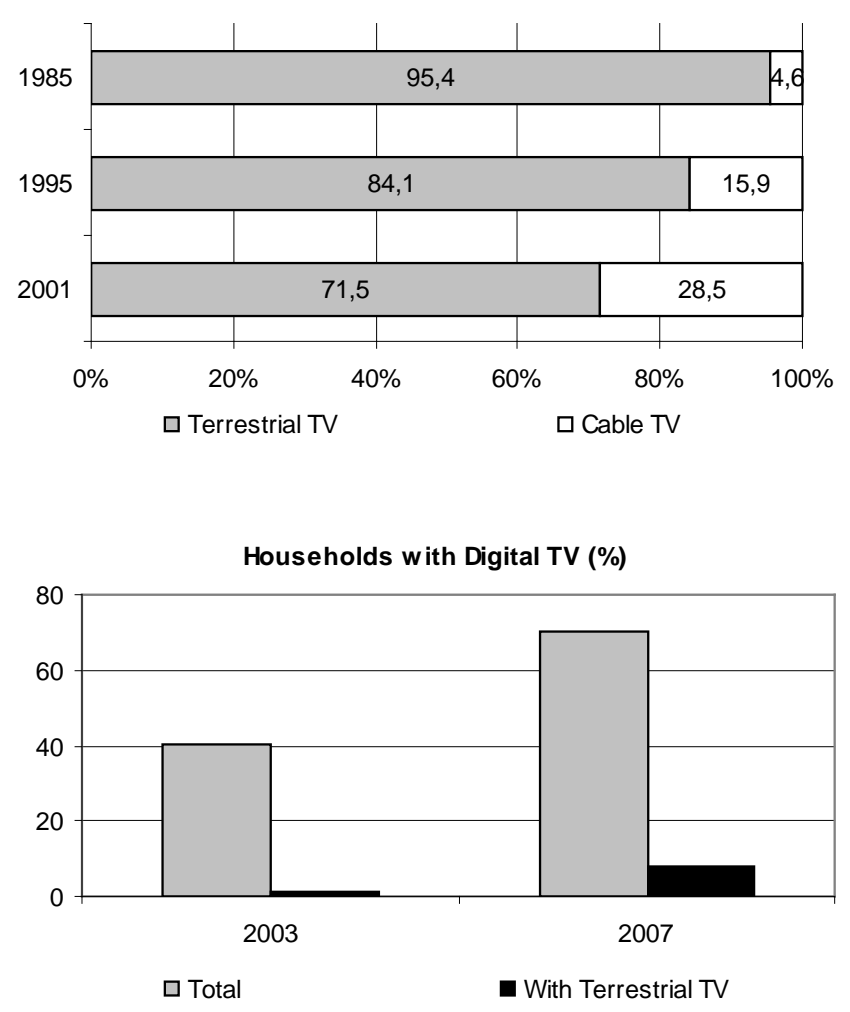

Figure 2. TV Market in the United States. Data based on Levy et al. (2002), OECD (2007) and Ofcom (2008)

According to Levy, et al. (2002), cable TV revenue from advertising has grown at a faster rate than those of terrestrial TV. Nevertheless, the volume of revenue from terrestrial networks is even greater and the number of satellite TV stations has grown in the last ten years. Additionally, the individual audience of a free-to-air network is still greater than the individual audience of the main cable TV channels. Therefore, the value of advertising time on free-to-air TV is still higher, which suggests that advertisers still prefer such vehicle rather than pay TV channels. Despite the downward trend, the same authors believe terrestrial channels have maintained a high attractiveness to advertisers and will remain having relevant market power.

According to Noam (2006), the concentration of U.S. terrestrial TV network, cable and satellite markets dropped in 1992 and increased again in $200 \mathrm{I}$ and 2005. Such dynamics was shaped by two factors: a) entry of multiple TV channels in the market $b$ ) regulatory changes that facilitated restrictions to concentration and encouraged mergers and acquisitions, as well as the entry of new telecommunications and TV enterprises in the market. Additionally, in recent decades, the United States have reduced program obligations as well as restrictions on media ownership and on the allocation of licenses for terrestrial TV operation (Galperin, 2004a), which may have affected the evolution of the American television market structure.

Noam (2006) also found that concentration in the segments in advanced stage of digitization (ie, cable TV and satellite) was higher than the average observed in the whole mass communication field. In cable TV sector, the market remained concentrated in spite of a larger number of channels.

Based on such findings and given the current market structure and the regulatory framework, one can infer that the concentration of mass communications is likely to have an upward trend after incorporating the technological advances of the information industry (i.e. digitization). This 
finding reinforces the idea that technology alone does not lead to a favorable dynamics for the expansion of the diversity of actors participating in such market (Noam, 2006).

With respect to digital terrestrial TV, currently in the United States it is set as a service similar to analog TV, with high-definition content but with no offer of additional channels. The adoption of high definition is a consequence of the main drivers of technological transition in such country: the revitalization of the American electronics industry in searching for new investment opportunities. It was also believed that a higher image quality would have enough appeal to halt the decline of terrestrial TV audience observed in the past decades (Galperin, 2004a).

Nowadays, one can observe a low penetration of digital terrestrial TV in the United States (as shown in Figure 2). The causes usually pointed out are the high price of high definition TV set and financial difficulties of some stations which delay the replacement of old equipment (Levy, et al., 2002). Moreover, the supply of high-definition content is still limited: until recently, only $10 \%$ of U.S. households had been enjoying high definition content out of a total including terrestrial TV, cable and satellite (Idate, 2007). All these factors have resulted so far in an expensive technology both for broadcasters and consumers, as well as a service of low appeal in the face of pay TV services that were already present in most households at the time when terrestrial digital TV was introduced (Galperin, 2003).

The American experience illustrates the importance of the actor network (Callon, 1987) on the shaping of impacts induced by new technologies. According to Galperin (2003), the low diffusion of digital TV reflected the difficulty to match different (and frequently opposite) interests between broadcasters, manufacturers and users. The unsuccessful attempt of coordination in the digital TV decision-making process in the United States resulted in an overvaluation of high-definition picture as fundamental for the success of the new technology. Such decision was made in favor of prevailing interests of consumer electronic manufacturers and contrary to broadcasters who would handle high investment costs of equipment substitution without benefiting from an equivalent increase in revenue. Nevertheless, until recently, terrestrial broadcasters have been the main beneficiaries, since the rules for use of additional frequency channel were relaxed in an attempt to reduce the pressure of the technological transition on these actors.

In order to encourage adhesion to terrestrial digital TV, some measures were adopted such as imposition of deadlines to broadcasters to exhibit part of the programming in high definition, as well as to consumer electronic manufacturers to offer progressively integrated digital TV sets (i.e., TV sets with embedded digital converters). At the same time, subsidies to digital set-top boxes were given in order to reduce prices to consumers. Recently, some local stations and public broadcasters have been testing the audience interest with an alternative strategy in order to spread its digital TV service: the transmission of multiple channels of programming with the image in standard definition (FCC, 2006).

With respect to content plurality and diversity in American television, different methodologies and divergent results characterize the research on the subject. By using a definition of diversity as a variety of genres shown on TV (eg, sitcoms, movies and news), Einstein (2004) noted that since the 1980s, the diversity of content has declined in spite of an increasing number of program channels due to the introduction of cable TV. The author concluded, therefore, that the diversity would not necessarily be achieved with a less concentrated market structure able to provide a higher volume of content.

But if the measure of diversity of content would be the time that terrestrial TV stations dedicate to exclusive news, the conclusion may be the opposite, as suggested by Alexander and Cunningham (2005), who found an inverse relationship between TV market concentration and content diversity in the U.S. market.

Another hypothesis on the relation between market concentration and diversity of content was proposed by Motta and Polo (2004). According to these authors, there would be a trade-off between quality and diversity of programming, since expenses with content would be proportionate to the audience. Stations that receive more revenue from advertisers would be more likely to produce higher quality content, which would increase barriers to entry and concentration. Under such conditions, only few stations would be able to offer a high-quality programming. Data from U.S. market presented by the authors illustrate such process: in 1993, the major networks devoted to 
programming $74 \%$ of their budget, while cable networks had a programming cost of $33 \%$ and local stations, of $23 \%$.

As the diverse studies mentioned have presented disparate findings, they illustrate the difficulty of establishing definitions, methodologies and evaluation criteria of the content diversity. The difficulty is accentuated by the lack of standard indicators and homogeneous criteria to assess the degree of plurality and diversity, despite the fair number of studies conducted (European Commission, 2007). The only consensus is that the equation between diversity and market concentration degrees is quite complex, and that the apparently intuitive hypothesis that a less concentrated market contributes to the plurality and diversity should be viewed cautiously.

\section{Discussion}

As presented before, the digital terrestrial TV in the UK aimed to stimulate the competition in industry. In order to reach such goal, one opted for permitting the provision of a larger number of TV program channels. Although the TV market regulation allowed the entry of new companies, the regulation let the major terrestrial broadcasters benefit from technological innovations by incorporating them in their strategies. Secondary data and studies about the TV sector suggest that such strategy has strengthened the traditional terrestrial TV companies in the face of competition to pay TV channels. This is the reason they have ensured their dominance in the market, despite the persisting threat of loss of audience and revenue market share in an increasingly competitive market, either because of the abundance of programming options or due to competition with other new media (internet). Additionally, coupled with the requirement to set a minimum percentage of independent content for broadcasters, the offer of more channels created the need to fill out new TV program schedules, raising the demand for content and thus favoring the industry of content production.

In turn, digital terrestrial TV in the United States was implemented in view of preserving the essential characteristics of analog TV service. The diffusion of new technology in American market has been slow due to high prices of receivers and low appeal of the service to the public whose majority subscribes to pay TV services. The fact that some American broadcasting stations have recently opted to offer multiple digital channels in order to test the interest of the audience revealed the need of traditional companies for changing their strategies to take profit of digital TV. With respect to plurality and diversity of content, studies have shown that providing a greater number of programs may not be translated automatically into greater heterogeneity of views held by the TV.

Regarding the Brazilian debate, the analysis of experiences in other countries permits to clearly identify at least two opportunities offered by new technology that can be applicable to Brazil provided they are allowed by regulation. They consist in strengthening the traditional terrestrial broadcasters and promoting the content production industry.

We should remember, however, that there are huge differences between Brazil and the cases presented. The most evident are the socio-economic ones. The low purchasing power of Brazilians can limit either the development of the television industry or the progress of new media whose business model is based on subscription. Such peculiar dynamics reinforces the market position of the traditional TV services and inhibits the adoption of TV service innovations, as the competition with paid medium (e.g. internet or pay TV) is less intense. Nevertheless, as the new ICT-based services start to spread in the Brazilian society, the traditional actors will need a more flexible regulation so as to allow the adoption of innovations to compete with the new services. Therefore, a favorable regulation would: (i) be more flexible to established TV broadcasters and, at the same time, (ii) reduce barriers to entry for smaller programmers in Brazilian market, thus (iii) contributing to the development and growth of a national content industry, which has a great potential of generating exportable high added-value goods (Katz, 2006, p.6) as well as employment and development (UNCTAD, 2004).

\section{Conclusions}

The international case studies showed that, despite reducing technological barriers to entry of new players in the TV industry, technological innovations have also the potential of benefiting the traditional players in such market. The case of United Kingdom illustrates a process in which the introduction of digital terrestrial TV has helped the existent free-to-air TV companies in the face of the competitive forces coming from a large number of 
cable and satellite channels. Such case shows that the traditional industry, although challenged, may be strengthened by new technologies, even if they imply in more dramatic changes in its market performance. The regulatory factors were also crucial. When comparing the cases of the United Kingdom with the United States, one can notice in the former an increasing demand for independent content, fostered by a regulation that allows the exploitation of new technological resources as much as favors independent content. In the latter case, the vertical integration of content production among the major American broadcast networks has widened after the elimination of the obligation of providing independent content.

Studies on other sub-sectors of American communications industry demonstrated that the digitalization of ICTs may have deepened the concentrating effects of economies of scale. The same trend could take place in terrestrial TV market. However, there is no consensus on how negative such effects would be to the plurality and diversity of content. A highly competitive environment with a low content diversity is as plausible as a highly concentrated market which provides high-quality content. It means that abundance of channels made possible by new technologies may constitute a necessary condition for expanding the participation of new actors and for raising the amount of content aired on TV, but it is neither sufficient to promote the content plurality nor is automatically translated into a wide range of opinions and points of view being spread. Usually proposed measures, such as the stimulus to independent producers and to public television companies, must have its effects on the plurality and diversity assessed with more precise criteria. But in strictly economic terms, certainly a growing demand for content is likely to boost the industry of content production.

Compared to Brazil, these countries present fundamental socio-economic differences. Yet Brazil is likely to benefit from the same opportunities offered by new TV technologies, probably in different ways and intensity. Digitization of TV may stimulate the market, with positive consequences such as generation of high qualified jobs and stimulation of a highly promising sector, as well as reinforcing the established actors, thus consolidating an environment for investment in promising sectors such as the production of content.

\section{References}

ALEXANDER, P. J., Cunningham, B. M., (2004). Diversity in broadcast television: An empirical study of local news. The international journal on media management, 6 (3\&4), PP. 176183.

ALVES, V. H. C., (2009). Preço impede que internet acompanhe expansão de PCs no Brasil. [online] TI Inside Online, 26 mar. Available at: http://www.tiinside.com.br/News.aspx!ID $=1261 \mid$ | $8 \& C=265$ [Accessed 24 March 2009].

BAJON, J., Villaret, S., (2004). High-Definition TV: Technological transition or new market? IDATE, Montpellier.

BOLAÑO, C. R. S., Brittos, V. C., (2007). A televisão brasileira na era digital: Exclusão, esfera pública e movimentos estruturantes. Paulus, São Paulo.

CALLON, M. (1987). Society in the making: the study of technology as a tool for sociological analysis. In Bijker, W.E. Hughes, T.P. and Pinch, T.F., ed. The Social Construction of Technological Systems: New Directions in the Sociology and History of Technology. The MIT Press, Pp. 83103.

EUROPEAN COMMISSION, (2003). On the transition from analogue to digital broadcasting (from digital 'switchover' to analogue 'switch-off'). COM(2003) 541. Brussels: European Commission.

EUROPEAN COMMISSION, (2007). Media pluralism in the member states of the European Union. Commission Staff Working Document. Brussels: European Commission.

EINSTEIN, M., (2004). Broadcast network television, 1955 2003: The pursuit of advertising and the decline of diversity. Journal of Media Economics, 17 (2), pp. I45- I 55.

FCC, (2006). Annual assessment of the status of competition in the market for the delivery of video programming (12th. Annual Report). Washington (DC): FCC. Available at: http://www.fcc.gov [Accessed 0I February 2007].

GALPERIN, H., (2003). Comunicación e integración en la era digital: un balance de la transición hacia la televisión digital en Brasil Y Argentina. Telos, [e-journal] 55. Available 
at: http://www.campusred.net/telos [Accessed 12 August 2006].

GALPERIN, H., (2004a). New television, old politics: the transition to digital TV in the United States and Britain. Cambridge: Cambridge University Press.

GALPERIN, H., (2004b). Beyond interests, ideas and technology: An institutional approach to communication and information policy. The Information Society, 20 (3), PP. 159-168.

GOODWIN, P., (2005). United Kingdom: Never mind the policy, feel the growth. In: A. Brown and R.G. Picard, ed. 2005. Digital terrestrial television in Europe. Mahwah, NJ: Lawrence Erlbaum Associates Publishers, Pp.15I-I80.

IDATE. Digiworld, (2007). Telecom, internet, media: The digital world's challenges. Montpellier: Idate.

KATZ, J., (2006). Tecnologías de la información y la comunicación e industrias culturales: Uma perspectiva latinoamericana. Series Cepal Documentos de Proyectos, 92. [Internet] Santiago: Cepal, 2006. Available at: http://www.eclac.cl [Accessed 27 October 2006].

LEVY, J., Ford-Livene, M., Levine, A., (2002). Broadcast television: Survivor in a sea of competition. FCC Office of Plans and Policy Working Papers Series, 37. [Internet] Washington (DC): FCC. Available at: http://www.fcc.gov [Accessed 27 October 2006].

MANSELL, R., (2004). Political economy, power and new media. New Media \& Society, 6 (I), pp. 96-I05.

MOTTA, M., Polo, M. (1997). Beyond the spectrum constraint: Concentration and entry in the broadcasting industry. In: M. Baldassarri and L. Lambertini, ed. 2003. Antitrust, Regulation And Competition. Palgrave Macmillan, pp. I0I-I34.

NELSON, R. R., Winter, S., (1977). In search of useful theory of innovation. Research Policy, 6 (I), pp. 36-66.

NOAM, E.M., (2006). The concentration of American media industries. In: TPRC (Telecommunications Policy Research Conference), 34th Research Conference on Communication, Information and Internet Policy. Arlington (VA), United States 29 Sep.-0I Oct. TPRC: Farnham (VA).
OECD, (2004a). Broadband audio-visual services: Market developments in OECD countries. Working Party on Telecommunications and Information Services Policies. [Internet] Paris: OECD. Available at: http://www.oecd.org [Accessed 31 January 2006].

OECD, (2004b). Competition in the video programming distribution market: Implications for regulators. Working Party on Telecommunications and Information Services Policies. [Internet] Paris: OECD. Available at: http://www.oecd.org [Accessed 3I January 2006].

OECD. (2007) OECD Communications Outlook 2007. Paris: OECD Publishing, 2007.

Ofcom, (2006). The Communications Market 2006. [Internet] London: Ofcom. Available at: www.ofcom.org.uk. [Accessed 02 October 2006].

Ofcom, (2007). The Communications Market 2007. [Internet] London: Ofcom. Available at: http://www.ofcom.org.uk [Accessed I5 July 2008].

Ofcom, (2008). The International Communications Market 2008. [Internet]: London: Ofcom. Available at: http://www.ofcom.org.uk [Accessed 02 February 2009].

OWEN, B. M., Wildman, S.S., (1992). Video Economics. Cambridge (MA), London: Harvard University Press.

PIZANI, J.I., (2005). TV digital, oportunidade e não um risco. Valor Econômico, 23 March.

PRESTON, P., (200I). Reshaping Communications: Technology, Information and Social Change. London \& Thousand Oaks (CA): Sage Publications.

RAVEN, J., Hoehn, T., Lancefield, D., Robinson, B. (2004). Economic analysis of the tv advertising market. [Internet] PriceWaterhouseCoopers. Available at: http://www.ofcom.org.uk [Accessed 05 January 2005].

SHAPIRO, C., Varian, H.R., (1999). Information Rules: a Strategic Guide to the Network Economy. Boston (MA): Harvard Business School Press.

TODREAS, T., (1999). Value creation and branding in television's digital age. Westport (CT): Quorum Books. 
Unctad, (2004). Creative Industries and Development. [Internet] Unctad Eleventh session. São Paulo: Unctad. Available at: http://www.unctad.org [Accessed 07 April 2008]

\section{About the authors}

Esther Menezes has a degree in Economics (200I) and MSc in Science and Technology Policy (2008), both from the University of Campinas (Unicamp). She is researcher at $\mathrm{CPqD}$ Foundation since 200I, where she has been working in research and consulting in the area of information technology and communication. Her main works referred to economic impacts of ICTs and evaluation of government policies, technology foresight studies, trends and scenarios of the evolution of ICT-based services, studies on the viability of ICT-based new products and services. She participated in several research projects, including works related to SBTVD (Brazilian Digital TV System).

Ruy de Quadros Carvalho has a degree in Administration from EAESP - Fundação Getúlio Vargas-SP, MSc in Political Science from University of Campinas (1980) and PhD in Development Economics from University Of Sussex (1993). He is professor at Science and Technology Policy Division of University of Campinas and has experience in administration and economics of technology with emphasis in strategic management of technological innovations. His main works were developed in the following themes: innovation strategies and models of innovation management, location and management of enterprises' innovative activities, strategic alignment tools, mapping of skills and technological capability and indicators of innovation. 